\title{
IZQUIERDAS, RÉGIMEN POLÍTICO, CUESTIÓN ÉTNICA Y CUESTIÓN SOCIAL EN ARGENTINA (1890-1912) \\ RICARDO FALCÓN
}

Texto publicado originalmente en Anuario de la Escuela de Historia, № 12, UNR, Rosario, 1986-87. Agradecemos a la dirección del Anuario la autorización para su reproducción en este número de ESTUDIOS SOCIALES.

En la primera década del siglo XX, el régimen inaugurado en 1880 comenzaba a evidenciar algunos síntomas profundos de desequilibrio. La economía, aunque con altibajos, no parecía constituir el elemento más preocupante: aún, el papel de la Argentina como "granero del mundo» parecía perpetuarse sin horizontes a la vista. Sin embargo, ciertos problemas políticos de envergadura y el estallido de lo que en la época se denominaba la "cuestión social», se vislumbraban como crecientes factores desestabilizantes. Tal como lo percibía Joaquín V. González, las transformaciones económicas seguían siendo el elemento legitimante fundamental de la elite gobernante heredera de la «generación del 80», pero el tratamiento de la situación política y social, requerían, al menos, reajustes ${ }^{1}$.

El régimen político, restrictivo, exclusivista, ya venía siendo cuestionado desde 1890 por algunos sectores segregados de la elite, particularmente por los Radicales y en alguna medida también por los Mitristas, pero ahora, las voces de alarma se alzaban no sólo en la oposición sino en el seno mismo de la elite gobernante. El frustrado levantamiento cívico-militar propiciado por los Radicales en 1905 y las sospechas -ciertas o ilusorias- de que la oposición política que ponía el énfasis en la crisis de representatividad, pudiera confluir directa o indirectamente con las fuerzas que parecían motorizar «la cuestión social», fueron para muchos la plena evidencia de la crisis en marcha.

También, «la cuestión social» había comenzado a manifestarse en la década anterior. Sin embargo, fue a partir de la huelga general de 1902, que hizo su plena irrupción en la escena nacional convirtiéndose desde entonces en un problema político de

${ }^{1}$ Joaquín V González, La reforma electoral argentina, Buenos Aires, Didot, 1902. 
primer orden. Entre ese año y 1910 tuvo lugar el período de mayor -por extensión y por intensidad-agitación social de la historia argentina contemporánea.

Entre ambas cuestiones -la crisis del régimen político y la oleada de agitación social- aparecía un tercer tema problemático, que en realidad se relacionaba estrechamente con las dos: la situación de los inmigrantes. Con la primera se relacionaba porque se encontraban marginados del régimen político y con la segunda porque esos trabajadores extranjeros eran en los centros urbanos los principales protagonistas de los movimientos huelguísticos.

La élite gobernante - por lo menos en algunos de sus segmentos- no se mostró indiferente frente a la situación que la amenazaba. Entre otros ejemplos, las reformas electorales de 1902 y 1912 como intentos de depuración y ampliación del régimen político y el frustrado proyecto de Código de Trabajo - «el Código González»- y la legislación del trabajo que le siguió, fueron los principales pasos de lo que se ha llamado "el reformismo oligárquico».

Así, durante toda la primera década del siglo XX, se desarrolló un debate en torno a las salidas posibles a la crisis del régimen. Pero, era un debate que la mayoría de las veces se desenvolvía en el terreno de la arena política y del movimiento de contestación social. En él intervenían los partidarios del «auto-reformismo» y también la oposición política, particularmente los Radicales.

Pero, no eran los únicos protagonistas. Lo que podemos llamar «las izquierdas» de la época también pesaban -directa e indirectamente- en la lucha por imponer una de las alternativas posibles a la crisis. Y si su presencia aparecía como mucho más notoria en relación a los movimientos sociales, no dejaba, sin embargo, de incidir en el conjunto de las cuestiones en juego.

Globalmente consideradas, estas izquierdas habían ido adquiriendo un peso político-sindical creciente en los principales centros urbanos compuestos mayoritariamente por extranjeros. Sus propuestas en relación a las cuestiones que hemos enunciado como fundamentales -crisis del régimen político, asimilación de los extranjeros y cuestión social- no eran indiferentes a la proporción en que ese peso creciente se distribuía entre las distintas corrientes que la componían.

Empleamos el término «izquierdas» para denominar a un conjunto de movimientos políticos expositores de ideologías que globalmente podríamos denominar de «contestación social», o si se quiere «anticapitalistas». Al utilizarlo en plural, se pretende subrayar - a pesar de los elementos comunes- la presencia de movimientos autónomos que presentan entre ellos importantes aspectos diferenciadores. 
Dentro de este espectro son fundamentalmente tres las tendencias que merecen, en ese período, el centro del análisis: el Anarquismo, el Socialismo y el Sindicalismo Revolucionario. Sin embargo, desde el punto de vista ideológico es necesario ir al interior de esos movimientos para detectar tendencias internas y etapas que permiten señalar variantes que requieren una consideración en particular.

Se trata entonces, de considerar las posturas y la actividad que en relación al régimen político, a los movimientos sociales y al problema de la asimilación de los inmigrantes, tuvieron esas corrientes entre 1890 y 1912, punto final del período marcado por la ley Sáenz Peña.

\section{LOS SOCIALISTAS}

En la primera década del nuevo siglo la política de los socialistas ya había adquirido un perfil definido: se trataba de la construcción de un partido basado en una doble estrategia hacia el socialismo. Por un lado se presentaba como un instrumento apto en la consecución de mejoras económicas y sociales para los trabajadores y por otro, como un partido de reformas democráticas, republicanas, "profundas». El nexo entre ambos aspectos era lo, que en la época se llamaba «la acción política» y que esencialmente se traducía en la acción legislativa parlamentaria. Ambos aspectos, formaban parte del «programa mínimo» en camino hacia la imposición del socialismo. Camino que presentaba un carácter fundamentalmente evolutivo².

Sin embargo, la relativa consolidación de esta política como dominante en las filas socialistas -relativa porque todavía en esos ańos debería sortear la oposición de los que luego serían los sindicalistas revolucionarios-, había requerido un escarpado camino, que supuso etapas diferentes y la presencia de tendencias contestatarias a la orientación que desde mediados de la década del noventa Juan

\footnotetext{
2 Existen numerosos trabajos para el estudio del socialismo argentino en sus primeras épocas. Entre otros: Emilio Corbiere, «Socialistas y anarquistas», en: Polémica, № 42, 1971; Ricardo Falcón, Los orígenes del movimiento obrero, Buenos Aires, CEAL, 1984: Ricardo Falcón, «Lucha de tendencias en los primeros congresos del Partido Obrero Socialista Argentino, 1896-1900», en: Apuntes, octubre-diciembre, 1979; Jacinto Oddone, Historia del socialismo argentino, Buenos Aires, 1934, La Vanguardia, 2 vols. Por otra parte, las colecciones de los periódicos Vorwärts y El Obrero para las épocas más lejanas y posteriormente la de La Vanguardia, que contiene el conjunto de las resoluciones y debates de los congresos partidarios y reuniones de sus organismos directivos; constituyen fuentes fundamentales para su estudio.
} 
B. Justo y su equipo imprimirían crecientemente a la política partidaria. Un breve análisis de estas alternativas de la política socialista revelará que los cambios y las polémicas apuntaban en lo esencial al corazón de las tres cuestiones que nos ocupan centralmente.

$\mathrm{Si}$ excluimos los que pueden constituir los antecedentes más remotos de la política socialista en Argentina -fundamentalmente las fracciones de la Primera Internacional que seguían los lineamientos de Marx y Engels-, los más directos se sitúan en los grupos actuantes en la década del ochenta. De ellos, sobresale el Verein Vorwärts, constituido en 1882 por un grupo de alemanes escapados de las persecuciones bismarckianas y que adoptaban el programa de la Social Democracia alemana. Hasta 1888 la actividad del Vorwärts será principalmente propagandística. Pero, a partir de esa fecha, coincidentemente con la iniciación en Argentina de un movimiento obrero, que a diferencia de las etapas precedentes, ya no presentará solución de continuidad, el grupo alemán desempeñará un papel importante en las luchas obreras del período y en la constitución del Comité Obrero Internacional, que organizará la celebración del $1^{\circ}$ de Mayo y en la posterior aparición del periódico El Obrero y en la creación de una Federación Obrera impulsada por los núcleos socialistas.

Alentados, muy probablemente, por el movimiento huelguístico que comenzado en 1888 se extendería hasta 1890 y extrayendo algunos elementos del tradicional arsenal teórico del socialismo internacional, particularmente de la experiencia alemana, los socialistas argentinos enfatizaron una orientación que vinculaba estrechamente lo político con lo sindical. De las páginas de El Obrero y en particular de los artículos de su principal animador, Germán Ave Lallemant, se desprende la idea de la construcción de un partido socialista a partir del desarrollo del movimiento sindical ${ }^{3}$. Por otra parte, Lallemant veía en la Revolución del 90, una posibilidad de revolución democrático-burguesa, a la cual los socialistas debían apoyar, sin perder su independencia ni abandonar la mira de sus objetivos históricos ${ }^{4}$.

El proceso de intensificación de las luchas sociales urbanas, entre 1888 y 1890 , había permitido a los socialistas abandonar la actividad eminentemente propagandística que era su eje central hasta entonces. Pero, paradójicamente, la tentativa

${ }^{3}$ El obrero, 12/12/1890.

${ }^{4}$ Ibíd. 
que comienzan a desplegar desde 1890, de desarrollar una actividad centrada en lo político-sindical, se vería afectada por las consecuencias de la crisis económica. En efecto, una de las repercusiones principales de la crisis fue la desocupación y una evidente retracción del movimiento huelguístico entre 1891 y por lo menos, mediados de 1894. En ese marco, las tentativas socialistas de construir federaciones obreras y de intensificar su actividad en el movimiento sindical, fueron necesariamente frágiles y efímeras.

Los fracasos de estos intentos llevarían a una parte de los socialistas argentinos a tratar de rectificar el rumbo. Desde mediados de 1892, una mayoría abandonaría la política centrada en lo sindical, para orientarse más decididamente a una actividad que privilegiaba la construcción de un partido socialista, sobre la base de un accionar político más definido.

Esta orientación será mucho más evidente a partir de 1894 y congregará a todos los grupos socialistas. En ese año se registran dos fenómenos que contribuirían a una modificación sustancial del perfil que hasta entonces mostraba la actividad socialista en Argentina.

Por un lado, al calor de la reactivación económica, que se va haciendo visible desde mediados de 1894, se reanuda el movimiento huelguístico, que en 1895 y 1896, tendrá una intensidad, particularmente en Buenos Aires y Rosario, nunca alcanzada hasta entonces. Esto, redundará en una reactivación de los lazos de los socialistas con el incipiente movimiento sindical y permitirá la incorporación a sus filas de algunos trabajadores.

Por otro lado, a partir de 1894, se incorporará al socialismo una serie de intelectuales, argentinos por nacimiento o naturalización, que configuraban lo que hemos denominado el «proto-intelectual de izquierda» en Argentina y que rápidamente ocuparán los principales espacios dirigentes. Esto suponía una doble modificación importante en un movimiento que hasta entonces había tenido en sus instancias dirigentes a una mayoría de obreros o artesanos, autodidactas, casi todos de origen extranjero y muchas veces recientemente llegados al país 5

Juan B. Justo, Leopoldo Lugones, Enrique Dickmann, José Ingenieros, Ángel Giménez, Nicolás Repetto, Roberto Payró, Nicanor Sarmiento, son algunos de esos intelectuales que desempeñarían papeles principales en las filas socialistas, en los últi-

${ }^{5}$ Véase nuestro trabajo Los orígenes..., op. cit. 
mos años de la década del noventa. Desde el punto de vista profesional tienen rasgos comunes: en su mayoría son abogados, médicos, periodistas, estudiantes, etc.

Pero, desde el punto de vista político también presentan ciertos, rasgos comunes. Muchos de ellos provienen de la frustrada experiencia de renovación democrática que habían parecido representar los levantamientos de 1890 e incluso el de 1893. Desencantados de esa experiencia, veían, ahora, en los crecientes movimientos sociales urbanos, un nuevo espacio político.

Una de las consecuencias -y no de las menos importantes- de esos cambios introducidos desde 1894, fue la iniciación de lo que podemos llamar el proceso de «argentinización» del socialismo. Esta «argentinización» aparecía estrechamente vinculada a una nueva estrategia que innovaba, aunque parcialmente, la que se había esbozado desde 1890. Los ejes fundamentales de esa nueva estrategia son los que terminarían por caracterizar el perfil de los socialistas en la primera década del siglo, y que ya hemos descripto anteriormente: la acción parlamentaria futura como instrumento fundamental para la conquista de reformas democráticas generales y económico-sociales de los trabajadores.

$\mathrm{La}$ «argentinización» se combinaba con la "acción política» en un punto fundamental: la necesidad de la naturalización de los extranjeros para que estos pudieran ejercer los derechos electorales. Y esta orientación se reflejaría no solamente en una intensa propaganda destinada a los trabajadores extranjeros en general, sino que también se implementaría como una exigencia para los propios militantes.

Ya tempranamente, en vísperas del congreso constitutivo de 1896, surgieron las primeras discrepancias contra esta exigencia. El agrupamiento sobre la base de criterios por origen étnico, nacional o de comunidad lingüística constituía una vieja tradición entre los socialistas en Argentina. En realidad, la costumbre se remontaba a la época de la Primera Internacional, entre 1872 y 1876, cuando se constituyó en Buenos Aires sobre la base de tres secciones, una de italianos, otra de franceses y una tercera de españoles.

Durante los años ochenta, aparte del ya mencionado Verein Vorwärts, hubo algunos otros grupos formados en torno a periódicos editados en idiomas extranjeros. Esta tendencia se reeditaría a principios de la década del noventa, cuando la actividad socialista se estructuraría sobre la base de cuatro grupos: el Fascio dei Lavoratori, de los italianos; el Vorwärts de los alemanes; Les Egaux, de los franceses y la Agrupación Socialista que congregaba a los hispano-hablantes.

Las primeras resistencias surgieron en 1895, cuando los representantes del Fascio 
dei Lavoratori -una parte de cuyos miembros provenían, antes de su integración al socialismo, de las filas de la izquierda republicana italiana- se negaron a formar parte del Comité Central que unificaba la actividad socialista, protestando contra una resolución que les imponía adquirir los derechos políticos -es decir, naturalizarse- para poder integrar dicho organismo ${ }^{6}$.

La cuestión volvería a plantearse en ocasión de los debates preparatorios al congreso de 1896, cuando se alzarán voces de protesta contra algunos artículos del estatuto adoptado por el congreso, que preveía que para formar parte de los órganos ejecutivos del partido y para participar en las decisiones fundamentales de la vida partidaria, como lo era, por ejemplo, la elección de los candidatos a diputados, se debía ser argentino por nacimiento o por naturalización ${ }^{7}$.

Paralelamente a este cuestionamiento, apareció, ya en el seno mismo del Congreso de 1896, otro, que arremetía contra lo que se consideraba una política «reformista». En esa ocasión, las cabezas visibles de la oposición a Juan B. Justo, serán José Ingenieros y Leopoldo Lugones, que por lo menos en dos puntos centrales, lograrán imponer emiendas al proyecto original de declaración constitutiva. Una de ellas, corrigió la propuesta que preveía la posibilidad de alianzas electorales con otros partidos. La segunda era de mayor envergadura y afectaba al corazón de la estrategia partidaria: la proposición de Juan B. Justo consideraba que una vez conquistado el poder político por los socialistas, el empleo de «otros medios»-eufemismo que ocultaba, apenas, hechos revolucionarios con apelación eventual a la violencia- era solamente una posibilidad; en cambio sus opositores consideraban inevitable la utilización de esos «otros medios» y lo eventual era sólo el momento de su empleo ${ }^{8}$.

El congreso aprobaría las dos emiendas y así en sus orígenes el partido socialista no excluía el recurso a una acción revolucionaria para la conquista del socialismo, aunque ésta debía ser precedida de la "acción política». Recién, en el segundo congreso, en 1898, Juan B. Justo lograría suprimir el párrafo final de la declaración adoptada en 1896, imponiendo así definitivamente, lo que sus opositores de entonces llamaban «reformismo». No obstante, en el curso de 1897 la lucha

\footnotetext{
6 Ídem, p. 98.

7 Ídem, p. 128.

${ }^{8}$ La Vanguardia, 01/08/1896.
} 
ideológica interna continuaría. El eje de la oposición pasaría por el periódico $\mathrm{La}$ Montaña, que se autoproclamaba «Socialista Revolucionario», que revelaba un tono libertario que sólo se diferenciaba de los anarquistas por el reconocimiento de la necesidad de «la acción política» y que tendría como principales animadores a Ingenieros y Lugones? .

Si la relativamente efímera oposición ejercida por La Montaña, enfatizaba la crítica al «reformismo» y soslayaba en cambio la resistencia a la naturalización de los extranjeros, en la medida que no negaba en principio la necesidad de la acción parlamentaria; por el contrario la fracción de los «Socialistas Colectivistas» que terminaría en una temporaria escisión -entre 1898 y 1900- tomaría a su cargo ambos argumentos conjuntamente ${ }^{10}$.

En realidad, las experiencias electorales que los socialistas hicieron en los últimos años del siglo XIX, no ayudaban en mucho a la estrategia preconizada por Juan B. Justo. Los magros resultados, se explican por un lado, por las características aleatorias y fraudulentas del sistema electoral, pero también por el hecho que muchos de los potenciales electores del socialismo eran extranjeros.

Superadas las oleadas contestatarias de 1897 y 1898, los socialistas encontrarían nuevas dificultades a partir del cambio de siglo. Es cierto que, paulatinamente iban logrando alguna inserción en el seno de los trabajadores y en el del creciente movimiento sindical. Sin embargo, allí encontrarían, ahora, rivales que les disputarían palmo a palmo esa incipiente inserción. Hacia fines del siglo, los anarquistas "organizadores» comenzaban a conquistar posiciones significativas en el seno del movimiento obrero, al mismo tiempo que iban extendiendo su influencia hacia otros sectores.

Hacia 1901, los socialistas podían jactarse-aunque no por mucho tiempo-que algunos aspectos de su prédica estaban dando frutos. En efecto, en ese año, por primera vez los anarquistas se mostraron dispuestos, luego de varios intentos fallidos en la década precedente, a confluir con los socialistas en una federación obrera unitaria. Así nacería, la FOA - más tarde FORA-y que estaría llamada a ser durante varios ańos un punto de referencia privilegiado para el movimiento obrero.

No obstante, pronto surgirían fuertes tensiones entre ambas corrientes que, a corto plazo, llevarían a una ruptura. En el fondo de esas tensiones estaban las

${ }^{9}$ Remitimos a nuestro artículo «Lucha de tendencias...», op. cit.

${ }^{10}$ lbíd. 
divergencias estratégicas que se expresarían particularmente en el debate en torno a la huelga general. A diferencia de sus adversarios, los socialistas no veían en ella un instrumento insurreccional y deploraban, además, algunos aspectos de la violencia que solía acompañar a estas manifestaciones. Para los socialistas, la huelga general era un instrumento que sólo resultaba idóneo en determinadas circunstancias -generalmente defensivas- mientras privilegiaban las huelgas parciales por reivindicaciones económico-sociales. Otra fuente de roces, era la tentativa socialista de vincular acción sindical y acción política, lo que necesariamente chocaba con el fuerte antipoliticismo de los anarquistas.

En minoría dentro de la Federación, los socialistas terminarían escindiéndose y constituyendo otra, la Unión General de Trabajadores (UGT), que aunque inferior en fuerza respecto a la FORA anarquista, lograría, no obstante, alguna representatividad en el terreno de la acción sindical. Otro hecho importante para los socialistas, fue la elección de su primer representante legislativo a nivel nacional, con el triunfo de Alfredo Palacios como diputado, en 1904. Además, ahora, la élite gobernante parecía valorarlos de alguna manera, en la medida que comenzaba a considerarlos como "oposición reconocida" al tenerlos en cuenta como potenciales interlocutores, lo que se expresaba en el trasfondo del proyecto de Código de Trabajo de 1904. Por otra parte, esos años coinciden con la emergencia de la vida política de las clases medias urbanas y en consecuencia un amplio sector de universitarios dividirá sus preferencias entre socialistas y radicales. Así, desde los primeros años del siglo los socialistas reciben en sus filas a numerosos intelectuales, al mismo tiempo que van logrando afiliaciones en otros sectores medios.

Paradójicamente, estos logros acelerarán una serie de contradicciones internas y abrirán el camino para una nueva y seria crisis que culminará en una escisión. Como en 1898, aunque no falten intelectuales, el cuestionamiento vendrá fundamentalmente de los sectores del partido vinculados a la actividad sindical.

Los dirigentes y militantes sindicales del socialismo estaban sometidos a fuertes presiones en su tentativa de llevar adelante una política que para los anarquistas y un sector de militantes sindicales independientes, aparecía como reformista en momentos en que los enfrentamientos entre el movimiento obrero y el Estado llegaban a puntos muy altos.

La presencia de Palacios en el Congreso y su acción por la consecución de reformas legislativas tendientes a mejorar el nivel de vida y las condiciones laborales de los trabajadores, al mismo tiempo que parecía convalidar la justeza de la estrategia 
planteada desde años antes por los dirigentes socialistas, aceleraba las críticas anarquistas y las tensiones internas entre «el ala sindical» y el «ala política».

La celeridad con la que los dirigentes partidarios intentaban públicamente deslindarse de los anarquistas en ciertas acciones de violencia de masas y en particular su firme condena del putch Radical de 1905, que le valió acusaciones de no solidarizarse con los sectores del movimiento que habían sido objeto de una dura represión, actuaba también como otro factor que precipitaba los conflictos con el sector de militantes sindicales.

En este marco, una repercusión mayor tendría el debate interno en torno a la posición que debería adoptar frente al proyecto de Código de Trabajo impulsado por el ministro Joaquín V. González. Este proyecto se inscribía dentro de una tentativa global de auto-reforma limitada del régimen oligárquico y que en el «aspecto político» había tenido su expresión en la reforma de la ley electoral en 1902.

El proyecto de Código, al mismo tiempo que incorporaba algunas de las reivindicaciones más sentidas por los trabajadores, incorporaba también algunos principios represivos de envergadura, como los contenidos en la Ley de Residencia y establecía un mecanismo de férrea regimentación de la actividad sindical. En el trasfondo de esta iniciativa se encontraba una «jugada» por parte de la elite destinada a aislar al anarquismo al mismo tiempo que se trataba de «integrar» a un sector del movimiento obrero por vía del partido socialista. El proyecto finalmente fracasaría porque encontraría una dura oposición en el movimiento obrero y también una escasa predisposición entre los sectores vinculados a la Unión Industrial Argentina.

Entre los socialistas surgirían dos grandes tendencias frente al proyecto: una que lo rechazaba frontalmente y otra que consideraba que debían apoyarse sus aspectos positivos y rechazarse los negativos. Lo novedoso, es que en el bloque que rechazaba de plano el proyecto González, aparecían argumentos que rompían con algunas de las concepciones teórico-políticas ya tradicionales del socialismo argentino. Por ejemplo, Luis Bernard, uno los militantes que encabezó la tendencia al rechazo global, cuestionaba no sólo el contenido del proyecto, sino el hecho mismo que pudiera apoyarse una iniciativa proveniente del Estado ${ }^{11}$.

Este contexto de crisis interna, favorecerá la penetración de ideas vinculadas con el sindicalismo revolucionario francés, con Arturo Labriola y Georges Sorel, que

${ }^{11}$ La Vanguardia, 25/08/1904. 
vehiculizadas por algunos intelectuales del partido harán carne en un importante sector de militantes sindicales. Una fracción interna preexistente encontrará así un corpus doctrinario que le dará coherencia ideológica. Nacía así, la tendencia Sindicalista Revolucionaria, primero como fracción interna y luego como corriente autónoma, El socialismo, sufría así una nueva sangría, probablemente la más importante que había tenido hasta entonces.

Las alternativas analizadas revelan las dificultades que encontraba la estrategia socialista en el marco político y social que caracterizaba la primera década del siglo. El número de afiliaciones anuales que había llegado a 2.192 en 1904 comenzó a descender bruscamente desde el año siguiente, manteniéndose en un nivel inferior a mil entre 1906 y 1908. Recién en 1909 registraría un cierto repunte, al alcanzar 1440 nuevas incorporaciones ${ }^{12}$.

Además, es probable que una cuota importante de esos nuevos afiliados no fueran obreros, sino que pertenecieran a distintas capas de sectores medios. A la pérdida de un contingente importante de sus militantes sindicales, el socialismo debería sumar la no renovación del mandato de Palacios. Será recién con la ampliación del régimen político, a través de la Ley Sáenz Peńa, que los socialistas recogerán los primeros frutos de una estrategia, que no parecía viable en el período oligárquico.

\section{LOS ANARQUISTAS}

Para los anarquistas, en cambio, la situación entre 1902 y 1910, se presentaba bastante más favorable. La FORA tenía en ciertas situaciones de conflicto social un evidente poder de convocatoria; el más importante de sus periódicos, La Protesta se editaba diariamente; su actividad propagandística se extendía más allá del plano sindical: centros feministas, antimilitaristas: escuelas racionalistas; configuraban lo que es posible denominar como los núcleos radiales de una "cultura anarquista».

También, como en el caso de los socialistas, los anarquistas habían recorrido un largo trayecto desde tres décadas antes, en cuyo transcurso se habían ido delimitando los rasgos esenciales de su perfil teórico-político. De los grupos pioneros de la década del ochenta surgirán dos grandes tendencias: los anarquistas «organizadores» y los «anti-organizadores», cuyo eje de división era la aceptación o rechazo

12 Partido Socialista Argentino, Movimiento Socialista y Obrero, Buenos Aires, P. S., 1910, p. 119. 
de ciertas formas de organización estables del movimiento; la participación en las organizaciones sindicales y en la lucha por reivindicaciones parciales. En Argentina este debate fue mucho más significativo que otro que transcurría paralelamente acerca de las formas de la futura sociedad y que escindía a los anarquistas entre «comunistas», «colectivistas» $\mathrm{y}$ «socialistas» ${ }^{13}$.

Entre 1890 y 1894 serían los «anti-organizadores» quienes llevarían la delantera. $\mathrm{Al}$ igual que los socialistas, los anarquistas «organizadores» encontrarían dificultades para su prédica en un marco social caracterizado por la desocupación y el reflujo del movimiento huelguístico que había tenido lugar entre 1888 y mediados de 1890 .

En cambio, la acción predominantemente propagandística y agitativa de los «anti-organizadores» encontrará una mejor situación para su desarrollo. Será el periódico El Perseguido, que en esos tempranos años llegará en algunas ocasiones a tirar 4.000 ejemplares, el principal portavoz de la corriente. Un fuerte tono antipoliticista, antiestatista, una cerrada oposición al establecimiento de vínculos entre los propios anarquistas que fueran más allá de la libre formación de «grupos por afinidad», un rechazo a los principios de «lucha de clases» y consecuentemente a la participación en las organizaciones obreras y a las huelgas parciales y un constante reclamo de la «propaganda por los hechos», eran los rasgos principales de la tendencia. Paradójicamente, este último punto quedará -al menos en el siglo XIXcomo una cuestión únicamente agitativa, ya que no habrá en esos años acciones de terrorismo político por parte de los anarquistas, que se limitarán a difundir los atentados realizados en Europa y a defender a sus ejecutores.

También como en el caso de los socialistas, los anarquistas adoptarán el principio de la organización de grupos sobre la base de criterios de origen étnico o comunidad lingüística. No obstante, las características de descentralización que tenía la actividad anarquista, hacía mucho más evidente la persistencia de estos criterios, a través de la proliferación de periódicos publicados en diferentes idiomas. Además, a diferencia de los socialistas, casi nada los incitaba a oponerse a la sobrevivencia de la identidad étnica. Su antipoliticismo descartaba cualquier preocupación por la naturalización de los extranjeros.

${ }^{13}$ Para los orígenes del anarquismo en Argentina, existen también varios trabajos; en particular; Diego Abad de Santillán, El movimiento anarquista en la Argentina, Buenos Aires, Argonauta, 1930 y laacov Oved, El anarquismo y el movimiento obrero en Argentina, México, Siglo XXI, 1978. 
Esta característica corresponderá tanto a los «anti-organizadores» como a los «organizadores». Este último sector comenzará a expandir su influencia entre los trabajadores extranjeros desde mediados de la década del 90 y dará en 1897 un paso decisivo en su consolidación como corriente, con la aparición del periódico La Protesta que funcionará como una especie de «frente unido» de distintos grupos «organizadores».

Los «organizadores» irán adquiriendo cada vez más un perfil «anarco-sindicalista», que ya visible en los últimos años del siglo XIX adquirirá rasgos definitivos en la década siguiente, particularmente por su acción en la FORA. Compartiendo con la otra tendencia su antipoliticismo y su anti-estatismo, se diferenciaban sin embargo, en la admisión de formas organizativas federativas para el movimiento anarquista y aceptaban la importancia de la organización sindical y de la lucha por demandas parciales aunque siempre en el camino de la huelga general insurreccional.

Las características del régimen político argentino no merecerán demasiados análisis por parte de los anarquistas. Aunque no dejarán de denostarlo, sus críticas particulares se disolvían en el marco de su oposición más amplia a cualquier forma estatal, incluso la parlamentaria.

En consecuencia, los anarquistas argentinos, combatirán y rechazarán de plano todas las tentativas de «auto-reforma» propiciadas por la élite gobernante. No habrá en el caso de los anarquistas un debate interno, como sí ocurrió con los socialistas, respecto al «Código González». No había diferenciaciones entre aspectos negativos y positivos del proyecto. Los considerados positivos por los socialistas, eran también negativos para los anarquistas, en la medida que se trataba de una injerencia estatal en la vida de los trabajadores ${ }^{14}$.

Con el mismo criterio se opondrán a la legislación laboral sancionada después del fracaso del proyecto de código de trabajo, a la constitución del Departamento Nacional del Trabajo y a toda forma de arbitraje o regulación estatal de los conflictos entre trabajo y capital. Por otra parte, el anti-estatismo anarquista se expresará a través del énfasis puesto en la agitación anti-autoritaria, anti-represiva y anti-militarista.

Su antipoliticismo los inhibirá para cualquier propuesta de reforma del régimen político. La cuestión se resolvería con la abolición del Estado y de toda forma de

${ }^{14}$ Alberto Castro y C. García Balsas, Críticas al proyecto González, Buenos Aires, edición del Grupo La Aurora, s/f. 
opresión, objetivos en cuya consecución desempeñaban un papel importante las tentativas de huelgas generales pre-insurreccionales que los anarquistas impulsaron entre 1902 y 1910.

En los anarquistas «organizadores» -que serán los que en la primera década del siglo XX tengan el mayor desarrollo dentro del anarquismo argentino- habrá lo que podemos denominar «un doble discurso». Por un lado, aparecía un «discurso de clase obrera", similar en algunos aspectos al que enunciaban los socialistas. Se expresaba en la importancia otorgada a la acción sindical, en la insistencia en las reivindicaciones de los trabajadores, en los planteos de «unidad en la acción» del movimiento obrero y por el rol que los trabajadores tenían en la acción insurreccional a través de la huelga general.

Pero, había también «un discurso de los oprimidos», que adquiría tanta importancia como el anterior y que los separaba más nítidamente de los socialistas e incluso de los sindicalistas revolucionarios. Era este aspecto el que los llevaba a subrayar lo antiautoritario en todos los niveles. Así, en el mismo plano que el movimiento de los trabajadores, aparecían reivindicaciones libertarias que incluía a otros sectores: la doble opresión de la mujer -por el Estado y la sociedad y por los varones- el antimilitarismo, los marginales, etc. Esto los llevaba a privilegiar junto a la acción sindical, otros «espacios». Así, la importancia dada «al mundo del consumo», que se expresaría, por ejemplo, en el énfasis puesto en la participación en la huelga de inquilinos de 1907, a diferencia de los socialistas. Es en este sentido y en comparación con un mayor "clasismo» de los sindicalistas revolucionarios, y hasta cierto punto, también de los socialistas, que es posible afirmar que las postulaciones anarquistas tenían un cierto carácter "populista».

Una buena cuota de los sectores que el anarquismo llegaba a influenciar, eran trabajadores manuales del sector servicios - puerto, transporte, etc.- y de las incipientes industrias, en los centros urbanos con población mayoritariamente de origen inmigratorio, especialmente en Buenos Aires y Rosario. Pero, también comprendía a un vasto sector de artesanos, trabajadores independientes, comerciantes ambulantes. Y también, al igual que el socialismo, comenzaba a atraer a un sector de los intelectuales, aunque probablemente en este terreno los anarquistas tuvieran una influencia menor.

Entre 1902 y 1910, los anarquistas llegaron a constituir en Argentina una fuerza política importante y que contaba -más allá de su antipoliticismo- en el juego polí- 
tico nacional. Esta fuerza provenía principalmente de su capacidad de convocatoria en el plano sindical, aunque éste no era -como dijimos- su único apoyo fuerte. La condena del autoritarismo estatal y el énfasis puesto en las demandas del movimiento social fueron los ejes centrales de la actividad anarquista en ese período. Sin duda las características del régimen político favorecían el crecimiento de la corriente.

En 1910 las tensiones llegarán al máximo en ocasión del Centenario y la derrota de la huelga general de ese año marcará el fin de una etapa. Los dos años siguientes serán de transición, pero inmediatamente después de la ley Sáenz Peña, comenzará a hacerse visible un declinio relativo del anarquismo, que aunque registre una breve resurrección entre 1919 y 1922, no volverá nunca a los niveles que había alcanzado entre 1895 y 1910. Dos hipótesis centrales pueden intentar explicar este declinio del anarquismo, que se traducirá también por el desplazamiento de su influencia a favor del socialismo y particularmente del sindicalismo revolucionario. En primer lugar, la ampliación del régimen político y la instauración de un marco democrático con la llegada del Radicalismo al poder y el establecimiento de un nuevo tipo de relaciones entre el Estado y los sindicatos, disminuirá los efectos de una prédica que como la anarquista, estaba centrada en lo anti-autoritario. En segundo lugar, las modificaciones que se van produciendo en la estructura productiva del país, plantearán para numerosos sectores de trabajadores la necesidad de una relación más fluida con el Estado. En este sentido, los sindicalistas revolucionarios, que irán modificando en parte, sus rígidas posturas antiestatistas de los primeros años, estarán en mejores condiciones de adaptarse a la nueva situación que los anarquistas.

\section{LOS SINDICALISTAS REVOLUCIONARIOS}

Como ya lo hemos señalado al referirnos a los socialistas, el sindicalismo revolucionario, nació como un producto de la fusión entre la crisis interna del Partido Socialista y la llegada a nuestras playas de los principios del sindicalismo revolucionario europeo, particularmente por vía francesa e italiana. No obstante, antes de la plena adopción de la ideología sindicalista revolucionaria, la fracción disidente fue esbozando un conjunto de planteos, que sin implicar una ruptura total con el socialismo argentino, la ubicaban como un «ala izquierda».

En un primer momento, la fracción disidente no renegará abruptamente del parlamentarismo sino que lo aceptará como una posibilidad de denuncia revolu- 
cionaria $^{15}$. De esta manera, se situaban así, en cierto modo, como una suerte de corriente socialdemócrata de izquierda, al estilo de las oposiciones europeas de la época. Sin embargo, en poco tiempo girarán hacia una ruptura de fondo con la política socialdemócrata.

Al pasar, constatando la rápida evolución de los disidentes socialistas de 1904, podemos interrogarnos acerca de la inexistencia en Argentina de corrientes socialdemócratas de izquierda, como las que -admitidos sus matices diferenciales- Lenin, Trotsky, Rosa Luxemburgo y otros, representaban en Europa. Habida cuenta, que el problema merece un análisis más exhaustivo, pareciera que entre el reformismo explícito de Juan B. Justo y el antipoliticismo anarquista o Sindicalista Revolucionario, en Argentina no hubiera habido «espacios» para otro tipo de políticas. La «vuelta al redil» de Ingenieros después de 1897 o el regreso al partido de los escindidos en 1898 e incluso la rápida evolución de los contestatarios de 1904 y 1905, parece confirmarlo.

Los sindicalistas revolucionarios compartirán el antipoliticismo y el antiestatismo de los anarquistas. Sin embargo, pronto se harán visibles, notorias diferencias entre ambas corrientes. Para los sindicalistas, el rechazo a la "acción política» no será sustituido por la preparación de la vía insurreccional, sino que el sindicato aparecerá como el eje presente y futuro de toda la vida social y política. Los sindicalistas revolucionarios ostentarán un planteo de «auto-educación» obrera, en el cual el recurso a la huelga general tenía menos las características insurreccionales de los anarquistas que un parentesco directo con la idea del mito soreliano como elemento educador y movilizador de la clase obrera ${ }^{16}$.

La «construcción de la clase obrera» pasará a ser uno de los planteos, centrales de la ideología Sindicalista Revolucionaria, a la cual debían subordinarse los aspectos secundarios. Es en este sentido, que se mostrarán más próximos de los socialistas que de los anarquistas, respecto a la intolerancia frente a los intentos de organización sobre principios étnicos. Todo particularismo debía ser borrado en función de la necesaria unidad obrera y la existencia de particularismos étnicos o nacionales actuaba como un elemento centrífugo frente a ese proceso de «construcción de la clase obrera».

\footnotetext{
${ }^{15}$ La acción socialista, 01/07/1905.

16 La concepción de los Sindicalistas Revolucionarios sobre la huelga general se encuentra expuesta en numerosos artículos, en las páginas de La acción socialista, particularmente en los años 1905, 1906 y 1907.
} 
El problema de la «unidad» se convertirá en un elemento decisivo en la polémica con los anarquistas. Los sindicalistas revolucionarios bombardearán a la FORA anarquista con propuesta de unidad sindical y de la constitución intermediaria de «pactos de solidaridad» en el camino de la unidad total. Esa propuesta unitaria de los sindicalistas revolucionarios no dejará de generar simpatías en ciertos sectores de trabajadores, alarmados muchas veces por las características que adquirían las disenciones entre las distintas corrientes del movimiento obrero. En todo este período, los anarquistas rechazarán las propuestas unitarias, con el argumento central que estaban de acuerdo con la unidad siempre y cuando ésta no anulara las posibilidades de ejercitar la propaganda de los principios del comunismo anárquico, lo que constituía para ellos la tarea fundamental ${ }^{17}$.

A pesar del evidente anti-intelectualismo de la propaganda Sindicalista Revolucionaria, el movimiento congregará desde un principio a un sector de intelectuales socialistas, que se integrarán posteriormente a la nueva corriente y continuarán en ella. No obstante, las principales figuras públicas serán algunos de los más conspicuos dirigentes sindicales socialistas de otrora. Es que, los sindicalistas revolucionarios alcanzarán algunos éxitos en su tentativa de penetrar en el seno de la masa de trabajadores, aunque todavía en esta primera década no lograrán desplazar la hegemonía anarquista.

En lo que al Estado y al régimen político concernía, los Sindicalistas Revolucionarios tendrán -bien que con fundamentaciones diferentes- posturas similares a las de los anarquistas. Rechazarán, en consecuencia, cualquier tentativa de reforma política y cualquier intento de «integración» de los trabajadores. Como hemos dicho, con el transcurso de los años los sindicalistas revolucionarios irán flexibilizando algunas de estas posiciones, No las que implicaban un rechazo a la «vida política», ya que se seguirán caracterizando por un profundo antiparlamentarismo, pero sí, en cambio, las que les permitirían una aproximación al Estado.

\section{¿POR QUÉ EL ANARQUISMO?}

Hemos analizado hasta aquí los rasgos centrales de cada una de las tres principales corrientes de la izquierda de la época, en relación a los tres temas que definimos como nuestra preocupación central: el régimen político, la cuestión de la asimila-

${ }^{17}$ La organización obrera, septiembre 1909. 
ción de los inmigrantes y la llamada «cuestión social». Intentemos ahora, entender el «éxito» comparativo de unas sobre otras, a través de la consideración particular de sus propuestas, relacionándolas con la situación argentina del momento.

Más concretamente: ¿por qué el anarquismo argentino logró prevalecer sobre los socialistas? ¿Por qué los socialistas encontraron dificultades mucho mayores en la aplicación de su estrategia y por qué surge de sus filas una corriente como el sindicalismo revolucionario, llamada posteriormente a ser hegemónica durante largo trecho en el movimiento social argentino?

Una aclaración previa se nos impone: la afirmación de la existencia de serias dificultades en la estructuración de la política socialista no puede, sin embargo, llevarnos a ignorar la importancia que tuvo como empresa política. En efecto, el socialismo argentino fue en esa época el intento más sólido de esa tendencia, en toda América Latina y muy probablemente más también que el de algunos países europeos «periféricos».

El caso del anarquismo argentino es también singular. El grado de desarrollo de esta corriente en ciudades como Rosario o Buenos Aires, es uno de los más altos del mundo - probablemente sólo comparable con el anarquismo barcelonés- dentro del espectro de los movimientos anarquistas urbanos de ese período.

Dos han sido las tradicionales explicaciones frente a este fenómeno. La primera, atribuye la fuerza del anarquismo argentino a la presencia de un alto porcentaje de inmigrantes de origen italiano o español, países considerados como de tradición anarquista. La segunda, hace descansar este éxito, en la persistencia en la Argentina urbana de rasgos pre-capitalistas. De esta manera, el anarquismo se correspondería con la presencia mayoritaria de una capa de trabajadores de características semi-artesanales, mientras que el marxismo sería la ideología más propia de los períodos industrializados.

La primera de las dos hipótesis nos parece la más insuficiente. Recientes investigaciones, tienden a demostrar que muchos de los militantes y seguidores del anarquismo adoptaron esas ideas en suelo argentino. Es cierto, que algunos de los dirigentes y militantes más experimentados, habían ya tenido experiencias vinculadas al anarquismo en sus países de origen. Pero, este no parece ser el caso de los más vastos sectores de trabajadores que de una u otra manera se relacionaban con el anarquismo argentino. Muchos de ellos provenían de regiones rurales, como en el caso del norte de Italia, en las cuales la influencia de la Iglesia no había sido casi 
quebrada. Por otra parte, ya en 1904, es visible la presencia de una nueva generación de dirigentes anarquistas, muchos de los cuales habían nacido en el país ${ }^{18}$.

La segunda hipótesis nos parece aceptable sólo parcialmente. Es cierto, que los anarquistas tuvieron influencias en gremios con características semiartesanales. Pero también las tuvieron en gremios similares, socialistas y sindicalistas revolucionarios. Además, los anarquistas lograron temprana influencia en algunas fábricas con alto grado de concentración de mano de obra y en gremios que no detentaban características semi-artesanales, como los portuarios, los estibadores rurales, los obreros del transporte urbano, etc.

Lo que sí nos parece cierto es que en los gremios con estructuración nacional y que requerían una necesaria relación con el Estado, el antiestatismo anarquista se convertirá en un obstáculo. Pero, esto -como veremos- no ocurrirá sino más adelante y precisamente cuando el propio Estado cambie de actitud hacia los sindicatos obreros. Por lo tanto esta cuestión debe situarse más en la esfera de lo político, que en el de una supuesta identidad «natural» ideología-grado de estructuración capitalista.

Nosotros pensamos que los motivos fundamentales del predominio del anarquismo sobre las otras corrientes de la izquierda, deben buscarse en sus posturas en torno a las tres cuestiones que hemos apuntado como decisivas en la época: las alternativas frente al régimen político, la cuestión étnica y la cuestión social.

En lo que hace al régimen político el antipoliticismo y el antiestatismo anarquista aparecían para los sectores populares como más simples y adecuados al tipo de Estado que enfrentaban, que las proposiciones socialistas. En efecto, su antipoliticismo que se traducía en el repudio a los partidos políticos y a las prácticas electorales y parlamentarias, estaba señalando, en realidad, una de las características centrales del régimen político vigente.

El sistema electoral era altamente fraudulento. Los partidos políticos que constituían la base del bloque conservador en el poder y aun algunos sectores semidisidentes, se fundamentaban en el clientelismo y en los apoyos que recibían desde el poder. El Radicalismo, que por su estructuración nacional centralizada, ha sido caracterizado como una tentativa de "partido político moderno", se mantenía marginado del régimen político y además, hasta por lo menos 1905, tendía a reclutar

18 Véase, laacov Oved, El anarquismo..., op. cit. 
fundamentalmente entre los núcleos de sectores populares «criollos» dejando de lado a la masa inmigratoria y presentando incluso algunos caracteres xenófobos en su propaganda. Los socialistas por el contrario, centraban su prédica política en los inmigrantes y en sus descendientes, pero eran víctimas no sólo del fraude, sino también del hecho que los extranjeros se encontraban marginados de la política. En síntesis, gran parte de la población estaba marginada del régimen político y la vida parlamentaria reflejaba mucho más el juego entre los distintos sectores de la élite, que el conjunto de las opciones políticas existentes en la sociedad.

En estas condiciones el rechazo simple y llano de los anarquistas se correspondía con la visión que los inmigrantes podían tener del régimen político. Los índices de naturalización permanecerán siempre muy bajos. ¿Qué incentivos podría tener un extranjero para naturalizarse frente a un régimen político tan poco atractivo para ellos como el existente? Como se ha analizado, la diferencia con los Estados Unidos es evidente. Allí existían aparatos políticos que reclutaban a los migrantes y de esta manera, integraban a los trabajadores extranjeros al régimen político democrático ${ }^{19}$. En Argentina, por el contrario, desde el punto de vista social, los extranjeros se encontraban suficientemente protegidos como para que se preocuparan por una naturalización que poco les ofrecía. La constitución nacional habla constantemente de "habitantes» no estableciendo diferencias entre nativos y extranjeros y cuando lo hace es para otorgar ciertas prorrogativas a estos últimos. Además, al continuar poseyendo la nacionalidad de su país de origen, los extranjeros encontraban -hasta cierto punto, es cierto- la protección de los cónsules.

Que los migrantes internacionales se mantuvieran marginados del régimen político, no significa que en el fondo tuvieran una actitud apolítica, ni antipolítica. Significa que encontraban otras formas de participación política, formas «no institucionales» si se quiere, al menos en algunos de sus segmentos. Las asociaciones por comunidad extranjera y una gama abigarrada de organizaciones "populares» e incluso el propio anarquismo, eran receptáculos de esa actividad política «no institucional».

En lo que respecta al antiestatismo, la propaganda anarquista tocaba otros de los puntos nodales de la política de la élite respecto a los trabajadores. Hasta principios del nuevo siglo, el Estado mantuvo una actitud prescindente ante los

19 Oscar Cornblit, «Inmigrantes y empresarios en la política argentina», en: Desarrollo Económico, vol. 6, №24, enero-marzo 1967. 
conflictos entre obreros y propietarios capitalistas. La resolución de estos conflictos quedaba librada al libre juego de correlación de fuerzas de las partes en pugna. Esta actitud sólo era alterada cuando esos conflictos alcanzaban dimensiones que amenazaban con alterar gravemente «el orden público» o cuando afectaban al corazón de la política agroexportadora, como en el caso de los ferroviarios. Allí, se ejercía una dura represión.

A partir de 1902 -aunque anteriormente ya se vislumbraran algunos síntomas aislados de cambio- la situación se modifica a partir de la huelga general de 1902. El Estado inaugura entonces una doble política hacia el movimiento de los trabajadores. Por un lado, domina la represión directa y decidida: la Ley de Residencia, la violencia policial en las huelgas y manifestaciones obreras, la puesta en semi-legalidad «vigilada» de los movimientos de izquierda. Esta es la actitud estatal que predomina ante la vista de los trabajadores.

Sin embargo, como hemos dicho, se inaugura casi paralelamente una segunda política destinada a lograr una «integración del movimiento obrero». Por un lado hay una tentativa, aunque parcial, de integrar limitadamente el movimiento obrero al régimen político, a partir de la reforma electoral que daría lugar a la elección de Alfredo Palacios. Por otro lado, hay un intento de «integración corporativa» del movimiento obrero a través del proyecto de Código de Trabajo, seguida luego por la sanción de alguna legislación sobre condiciones de trabajo y la creación del Departamento Nacional del Trabajo. Sin embargo, esta segunda faz de la política oficial frente a los sectores populares, que se expresaba de una manera harto retaceada, no llegaba a ocultar el aspecto dominantemente represivo de la política oficial.

Frente a una política estatal de este tipo, la propaganda antiestatista de los anarquistas no encontraría demasiadas contradicciones. Su denuncia implacable y sistemática del Estado como instrumento de opresión, parecía convalidada por la actitud de la élite hacia los trabajadores. Señalemos, además, que más allá de algún tipo de intervención limitada del Estado en el proceso de recepción de los inmigrantes en las primeras épocas, éste se mantenía totalmente prescindente en lo que hacía a los trabajadores en materia de mutualismo, seguridad social, etc.

Para los socialistas, en cambio, la cuestión era mucho más compleja. Pese a sus denuncias sobre las características del régimen político vigente, los socialistas tenían finalmente frente a él, una actitud «positiva». Esta se traducía en su insistencia en la necesidad de participar en los procesos electorales y en utilizar al parlamento. Más allá, de que, salvo circunstancias relativamente excepcionales, como las que 
rodearon la elección de Palacios en 1904 y que no se repetirían hasta después de la sanción de la ley Sáenz Peña, los socialistas fuera víctimas del fraude y del carácter aleatorio del conjunto del sistema político. El abstencionismo Radical no hacía tampoco demasiado cómoda la posición de los socialistas.

La empresa era realmente ciclópea: se trataba de convencer a los trabajadores extranjeros de naturalizarse argentinos y ejercer sus derechos políticos y confiar en la acción legislativa, frente a un sistema que no era un garante serio para ninguna de estas iniciativas.

Los sindicalistas revolucionarios, por su parte, y al menos en los períodos iniciales de su existencia como corriente autónoma, manifestaron un antipoliticismo y un antiestatismo en muchos aspectos similar al de los anarquistas. No era casual entonces, que aunque salidos del seno del partido socialista los sindicalistas revolucionarios, establecieran, particularmente, una competencia con los anarquistas.

El segundo gran problema, en torno al cual los anarquistas tenían una postura que recibía una mejor acogida entre los sectores populares, era el de los inmigrantes. Nos parece necesario reseñar brevemente a qué nos estamos refiriendo cuando hablamos de "cuestión étnica».

Como se sabe, la Argentina fue, de todos los países que vivieron grandes procesos de migraciones internacionales, el que recibió, en términos relativos, la mayor proporción de extranjeros en referencia a la población nativa. En el período que nos ocupa, en algunos grandes centros urbanos, especialmente Buenos Aires y Rosario, el porcentaje de extranjeros oscilaba en alrededor del 50\%.

Una heterogénea masa de extranjeros poblaba, ahora, la Argentina. Heterogeneidad, que cubría tanto los aspectos étnicos como los políticos o culturales. Los extranjeros - particularmente los que conformaban los sectores populares- tendían a insertarse en el plano económico y relativamente en el social. Sin embargo, no existían demasiados incentivos como para que aceptaran de buen grado un proceso de «aculturación». Una de las características de la situación de los extranjeros en gran parte del siglo XIX y XX en Argentina, fue la tendencia a la persistencia de la identidad étnica. Como hemos dicho, pocos incentivos existían como para que los inmigrantes abandonaran voluntariamente sus principales rasgos culturales y se integraran a esa «nueva cultura nacional en formación».

Aunque -según estimaciones- aproximadamente una mitad de los extranjeros que llegaron a la Argentina, la abandonaron en algún momento y por diversas razones, quienes se afincaban, encontraban mayoritariamente algunas posibilidades de 
inserción en la estructura productiva, aunque en niveles desiguales. Pero, como ya hemos señalado, esta «integración» económico-social, podía realizarse sin necesidad de incorporarse al régimen político, ni desistir de su identidad «étnico-cultural».

Desde el punto de vista del discurso socialista o Sindicalista Revolucionario las tendencias a mantener los particularismos étnicos o nacionales que reflejaba gran parte de los trabajadores inmigrantes, significaban obstáculos en la «construcción de la clase obrera». Aunque formulado con matices diferentes, ambas proposiciones tendían a un alto grado de unidad y homogeneidad de los trabajadores, que necesariamente excluían particularismos centrífugos como los representados por la tendencia de los trabajadores extranjeros a agruparse en tomo a criterios étnicos, nacionales o lingüísticos.

Para los sindicalistas revolucionarios, la "construcción de la clase obrera», inspirada por un criterio netamente clasista, pasaba sobre todo por la unidad obrera, que debía tener como eje el sindicato y la actividad sindical solidaria. En este sentido, los particularismos por nacionalidad extranjera, eran vistos como un obstáculo para la necesaria organización unitaria de la clase obrera. Diversos artículos en periódicos gremiales vinculados al sindicalismo revolucionario, testimonian esta vocación clasista ${ }^{20}$.

En los socialistas existía una predisposición similar a rechazar las tendencias a la persistencia de la identidad étnica y sus formas organizativas derivadas, por parte de los trabajadores extranjeros. Aunque aquí el eje nucleador no fuera como en el caso de los sindicalistas revolucionarios, el sindicato sino el partido político, el criterio clasista también se imponía, de alguna manera. Ya hemos visto, como esa concepción llevó a los socialistas, durante el siglo XIX, a propiciar incluso la naturalización dentro de sus propias filas. Durante la primera década del siglo siguiente continuará una tendencia de este tipo que se expresará -salvo cortas excepciones- por el repudio a toda forma de organización gremial que se basara en criterios étnicos, culturales, nacionales o religiosos ${ }^{21}$.

\footnotetext{
${ }^{20}$ Véase, por ejemplo, El obrero constructor de rodados, julio 1911.

${ }^{21}$ Un ejemplo, encontramos en el artículo titulado «Deplorable», aparecido en La Vanguardia del 26 de octubre de 1901 y en el cual se afirmaba que el carácter cosmopolita de la clase obrera argentina constituye un obstáculo para su organización política y económica. Agregaba que la existencia de diferencias culturales y de nacionalidad era un elemento negativo y criticaba la organización sobre bases de ese tipo o incluso «religiosas», como en el caso de los Círculos Obreros Católicos o de la Sociedad de Obreros Israelitas.
} 
Por el contrario, los anarquistas inspirados por sus concepciones profundamente antipatrióticas e internacionalistas, sumadas a su repudio al régimen político, no evidenciarían ningún interés particular por ahogar las tendencias al agrupamiento sobre bases étnicas, que mostrarían ciertas capas de trabajadores. Durante todo el período coexistirán los grupos anarquistas estructurados sobre criterios programáticos, con los formados en torno a concepciones corporativas y los nucleados a partir de origen étnico. Incluso, durante cierto tiempo, La Protesta, aparecerá en forma bilingüe, añadiendo a su tradicional publicación en castellano, una página en idish.

Esta tolerancia de los anarquistas frente a las tendencias de los extranjeros respecto al mantenimiento de la identidad étnica, les evitará choques con ciertos sectores de los trabajadores. Esta cuestión, aparecerá como más importante, si se tiene en cuenta que desde principios de siglo, desde el propio seno de la élite gobernante provendrán presiones destinadas a «nacionalizar» a los extranjeros.

En efecto, la multiplicidad étnica aparecía para la élite dirigente como un mosaico variopinto, que requería la «creación» de la nacionalidad argentina, como un elemento fundamental para la existencia de bases estables ideológicas de dominación. Había que crear, como lo señalaría Otto Bauer y el «austromarxismo», una "comunidad carácter» que supone la idea de nación. Desde 1880 había sin duda en Argentina, un «Estado Nación», que había supuesto la unidad de los particularismos provinciales en torno a un poder político central, territorialmente integrado. Sin embargo, era menos evidente que frente a la «dispersión étnica» que había supuesto la oleada inmigratoria, existiera una «nacionalidad argentina». La incapacidad de generar un régimen político integrador de los trabajadores extranjeros -como ocurrió de alguna manera en Estados Unidos- aceleraba por parte de la dite la necesidad de crear otros elementos de dominación. El recurso a «lo nacional», establecido particularmente en el plano de lo simbólico, se expresará a través del culto a los símbolos patrios, la acción «nacionalizadora» atribuida al nuevo régimen militar después de la ley del Servicio Militar Obligatorio, la acción a través de la educación pública. Esta tentativa, se reflejará en el plano de la literatura política a través de obras, como las de Ricardo Rojas y Manuel Gálvez ${ }^{22}$.

Esta tentativa de «nacionalización forzada» agregará un elemento adicional de

${ }^{22}$ Nos referimos en el caso de Gálvez a El diario de Gabriel Quiroga y en el de Rojas a La restauración nacionalista y Blasón de Plata, entre otras producciones del momento. 
simpatía hacia la actitud anarquista de tolerancia con los particularismos étnicos. Los socialistas, en cambio, participarán de alguna manera de ese proceso de «argentinización", aun cuando su óptica fuera parcialmente diferente a la de la élite. Todo lo que hasta ahora hemos expuesto sobre la actitud de los socialistas frente a la "cuestión de la nacionalidad» tiende a desmentir una profusa literatura que ha tendido a situar a esa tendencia como de «espaldas» a lo nacional.

En realidad, estas «acusaciones», provienen de lo que ideológica e históricamente podemos denominar como el «tercer revisiomismo», que aparece como una suma de «nacionalismo de izquierda» con ingredientes teóricos provenientes del marxismo y que conoció su época de expansión en los años sesenta y comienzos del setenta ${ }^{23}$. Lo que está, probablemente, en la base de la confusión que introduce la crítica de este «tercer revisionismo», es la identificación de «liberalismo» con «extranjerismo». Pero, lo paradójico es que los dirigentes socialistas recurrían a las tradiciones ideológicas liberales argentinas del siglo XIX -particularmente su reivindicación de la Generación del 37- como parte de una tentativa de encontrar «filiaciones nacionales» a sus postulaciones teórico-políticas de comienzos del siglo veinte.

El último de los tres grandes problemas que enfrentaban las izquierdas del cambio de siglo, es la llamada «cuestión social». Durante las primeras décadas de la segunda mitad del siglo XIX, esta «cuestión social» aparecía como relativamente mitigada. En efecto, los conflictos entre capital y trabajo se resolvían generalmente de forma individual y pacífica en el marco de los pequeños talleres artesanales y comercios basados muchas veces en una explotación de tipo familiar. El relativamente alto grado de movilidad social que existía para los migrantes internacionales en la Argentina urbana de la época, actuaba como «un colchón» impidiendo, que salvo excepciones, las situaciones conflictivas conllevaran formas agudas de violencia social. Era la época, en la que muchos trabajadores preferían el trabajo a destajo y que aún las preocupaciones por limitar la jornada de trabajo, no estaban demasiado extendidas.

En los últimos diez años del siglo pasado y en los primeros del actual, la tendencia dominante entre los trabajadores urbanos comienza a cambiar. El rechazo a las condiciones vigentes, ahora, se hace cada vez más visible y va acompañando una mayor estructuración capitalista de las relaciones de trabajo. La jornada de

${ }^{23}$ Nos referimos a autores como Jorge Abelardo Ramos, Rodolfo Puiggrós, Juan José Hernández Arregui, entre otros. 
ocho horas, los movimientos por la abolición del trabajo a destajo, los reclamos de aumentos salariales y de un amplio conjunto de reivindicaciones laborales y sociales, comienzan a ser tomadas por los sindicatos y otros movimientos sociales.

Las ya analizadas respuestas del Estado y la intransigencia de los capitalistas, que se negaban a reconocer de pleno derecho, e incluso a veces de hecho, a los sindicatos obreros, llevaban crecientemente a los trabajadores a adoptar las formas de la «acción directa» para la consecución de sus objetivos.

Los anarquistas promoverán estas formas de lucha sin restricción alguna. Frente a la intransigencia y la represión estatal y patronal impulsarán la acción directa y la huelga general como instrumento de lucha fundamental. La articulación entre luchas parciales y huelga general no presentaba para ellos, desde el punto de vista teórico, grandes dificultades, en la medida que ambos momentos confluían en la perspectiva de la huelga general insurreccional.

También en este terreno la situación de los socialistas era más compleja. La estrategia insurreccional estaba claramente descartada para los socialistas. Las huelgas parciales tenían objetivos concretos y precisos; mejorar las condiciones en el ámbito de la producción. La huelga general sólo era aceptable con fines defensivos en determinadas circunstancias. Una perspectiva insurreccional hubiera sido totalmente incompatible con la estrategia socialista, que descansaba en un tránsito evolutivo hacia el socialismo y en una concepción de las luchas sociales como una lucha de clases no antagónica.

Además, el movimiento sindical era sólo uno de los elementos de una triple articulación en la lucha por la cuestión social. Los otros dos eran la acción parlamentaria destinada a conseguir una legislación protectora del trabajo y diversas formas no sindicales de acción social, como el cooperativismo.

En una sociedad con las características que hemos descripto, la tentativa socialista de articular la acción sindical y la acción política se presentaba como una tarea difícil. Más aún, el socialismo argentino tendrá a lo largo de su historia, enormes problemas para poder congeniar ambos elementos. Cada vez que lograban una cierta inserción en los medios obreros e intentaban combinarla con la acción política, se generaban fuertes tensiones, crisis e incluso escisiones. Las luchas internas y rupturas de 1897 y 1898-1900; las de 1904-1906, las de 1918-1921 y aun las de fines de la década del treinta y del período preperonista, parecen confirmarlo. En realidad, en la Argentina de la primera mitad del siglo XX, en lo que concierne a «la integración de los trabajadores», lo político y lo corporativo parecían excluirse 
mutuamente. Y así lo expresan, de alguna manera, los «éxitos» de la acción anarquista, en una primera época y del sindicalismo revolucionario, "corporativista» y antipoliticista -aunque no antiestatista- posteriormente.

Si el clima político imperante explicaba las ventajas que los anarquistas obtenían respecto a los socialistas en la carrera por conseguir apoyo de los sectores populares, en cambio, tendrán rivales más fuertes en los sindicalistas revolucionarios. Estos, también pondrán un profundo énfasis en los movimientos reivindicativos y apelarán también a formas de acción directa.

Pero, tenían sobre los anarquistas una ventaja adicional. Su constante reclamo de la unidad obrera no dejará de generar simpatías entre los trabajadores. Sus propuestas de «Pactos de Solidaridad» y de fusión de las federaciones obreras, irán acompañadas de una propaganda destinada a denunciar el sectarismo anarquis$\mathrm{ta}^{24}$. De todas maneras, la aparición como corriente autónoma se dio casi hacia final del período del régimen oligárquico y en consecuencia no hubo un tiempo suficiente como para medir los resultados de la confrontación. Cuando esta se dé en las nuevas circunstancias creadas después de la ley Sáenz Peña, los sindicalistas revolucionarios, resultarán triunfantes.

En síntesis: el auge del anarquismo en el período que estudiamos aparece avalado por sus posturas frente al Estado y al régimen político ante los cuales preconizaban el rechazo simple y llano; frente a la integración de los migrantes internacionales, ante la cual respetaban la tendencia a la persistencia de la identidad étnica; y finalmente por su insistencia en las reivindicaciones económicas y sociales, que terminaban por ser en su accionar las cuestiones fundamentales.

\section{LAS IZQUIERDAS Y LA CRISIS DEL RÉGIMEN POLÍTICO}

La importancia de la influencia alcanzada por el anarquismo entre los sectores populares urbanos y también el crecimiento del sindicalismo revolucionario hacia el fin del período, revertían a su turno sobre la crisis del régimen político y no dejaban de incidir, en alguna medida, sobre las iniciativas de autorreforma.

Las huelgas y movilizaciones que estos sectores impulsaban, creaban, como ya

${ }^{24}$ La acción socialista, 15/09/1907. 
dijimos, un clima de agitación social casi constante. El empleo de la represión fuerte y sistemática no otorgaba mayor credibilidad a la élite gobernante, sino que por el contrario ponía en evidencia su necesidad de emplear este recurso, carente de cualquier forma de consenso entre los sectores populares urbanos.

Además, la oposición anarquista y las tensiones que ésta había generado en las filas socialistas, había sido uno de los factores dominantes en el fracaso del proyecto de Código de Trabajo, que tal como analizamos, constituía un intento de «integración» de un sector de los trabajadores. Posteriormente, los anarquistas y los sindicalistas revolucionarios, continuaron su posición antiestatista, boicoteando y hostigando la tarea del Departamento Nacional de Trabajo y subrayando en su propaganda, las limitaciones y violaciones a la legislación laboral -escasa por cierto- que se fue sancionando desde 1904.

Estas corrientes de izquierda constituían también una amenaza, en la medida que las repercusiones del movimiento social parecían sumarse a los que provenían de la oposición política. Aunque esta confluencia no fue directa, sino indirecta, como en el caso de la aplicación del estado de sitio después de la conspiración Radical de 1905, incidía como un factor adicional de crisis.

Por el contrario, los socialistas -si bien no serán escatimados por los «desbordes» de la represión en ciertas ocasiones- eran considerados como una eventual oposición «legal». En todo caso, no obstante sus críticas al conjunto del régimen oligárquico, su actitud era más «positiva» que la de los Radicales. Pero, se trataba de «un círculo vicioso", porque eran las características mismas del régimen político las que impedían que los socialistas se convirtieran en una oposición aceptada con peso suficiente como para incorporar al juego político a un sector importante de los trabajadores.

Pese a las circunstancias señaladas y en una marcha con altibajos, los socialistas habían logrado una presencia política indudable, por lo menos en el ámbito de la Capital Federal. Pero, recién darán «el salto» con la ampliación del régimen político. Pero entonces enfrentarán un nuevo rival: el Radicalismo abandona la abstención y se lanza de lleno al juego político disputando exitosamente a los socialistas una franja importante de las emergentes clases medias y de los sectores populares.

En el caso de los anarquistas y también en el de los sindicalistas revolucionarios, su poder de convocatoria también presentaría límites. En ciertas circunstancias revelaban una indudable capacidad para generar la adhesión de importantes sectores de trabajadores en la lucha por reivindicaciones sociales y democratizantes. Pero, como ocurrió en particular en el caso de la huelga general de 1910, esta adhesión 
tendría límites precisos. Ambas tendencias pretendieron darle a ese movimiento un carácter de cuestionamiento político abierto «al sistema» y de atropellar los símbolos que la burguesía había montado en torno al Centenario. Los trabajadores los siguieron en los primeros momentos de la huelga, pero luego los militantes quedaron librados a su suerte frente a la represión más dura que habían debido soportar hasta entonces.

La huelga general de 1910 terminó en una profunda derrota para el movimiento obrero. Lo que estaba evidenciando eran los límites que tenía la táctica de la huelga general en la situación de la época. Esa derrota marca el momento de la iniciación del declinio de los anarquistas -aunque los síntomas más claros se harán visibles tiempo después- y el comienzo del viraje de posiciones de los sindicalistas revolucionarios. Y creó también, ciertas condiciones que facilitaron el proceso de tránsito que significó la sanción de la Ley Sáenz Peña. 